\title{
Acute Kidney Injury Secondary to Rhabdomyolysis: A Rare Complication of Low-Energy Trauma
}

\author{
Sumit Banerjee ${ }^{1}$, Akshat Gupta ${ }^{1}$, Jeshwanth $\mathrm{N}^{1}$
}

Learning Point of the Article:

The key learning objective from this article is that rhabdomyolysis induced acute kidney injury must always be ruled out in geriatric patients of trivial trauma with extensive soft tissue bruising, as the condition has a very favorable prognosis, if promptly detected and treated.

\section{Abstract}

Introduction: Crush syndrome refers to the systemic manifestation of muscle cell injury following release of myocyte contents into the blood circulation. It is seen most commonly in patients sustaining high-energy trauma. Acute kidney injury is one of the most serious complications of crush syndrome and is an important cause of mortality in these patients. In contrast, the occurrence of rhabdomyolysis in patients sustaining lowenergy trauma is sparsely reported in the literature. The authors report one such rare case.

Case Report: The patient was a 77-year-old hypertensive male who presented to the emergency following an episode of slip and fall at home. After prompt resuscitation, he was sent for radiological evaluation which revealed fractures of the left inter-trochanteric femur and left proximal humerus. Meanwhile, laboratory investigations showed grossly deranged renal parameters, along with elevated serum creatinine phosphokinase levels (more than 5 times the baseline). A diagnosis of acute kidney injury secondary to traumatic rhabdomyolysis was made. Medical management included adequate intravenous fluid administration combined with strict input-output monitoring. Subsequently, the patient underwent closed reduction and internal fixation of the inter-trochanteric femur fracture with a proximal femoral nail. However, fracture of the proximal humerus was managed non-operatively with sling immobilization as patient refused to give consent for a second surgery.

Conclusion: Although rare, acute kidney injury secondary to rhabdomyolysis can occur in patients with low-energy trauma. It is important not to confuse it with chronic renal insufficiency, especially in geriatrics many of whom are long-standing hypertensives.

Keywords: Acute kidney injury, crush syndrome, low-energy trauma, rhabdomyolysis.

\section{Introduction}

Crush injury refers to injury resulting from direct physical trauma to the muscles secondary to a crushing force $[1,2]$. Crush syndrome, on the other hand, is the systemic manifestation of traumatic rhabdomyolysis due to breakdown of myocytes and subsequent release of their contents into blood circulation $[1,2]$. The condition was first described by Eric Bywaters during World War II, and therefore, it is also sometimes referred to as Bywater's syndrome [3].

Although traditionally associated with wartime injuries, crush syndrome is also seen in civilian life, especially, in incidences involving high-energy trauma-collapse of heavy structures during earthquakes/landslides, road-traffic accidents, assaults, etc. $[2,4,5]$. On an average, the incidence of crush syndrome in trauma patients ranges from 2 to $15 \%[1,6]$. It can go as high as $30 \%$ in earthquake victims [6]. Rarely, crush syndrome and rhabdomyolysis can also be seen in certain low-energy traumatic injuries which result in prolonged immobilization of the body, for example, positioning during surgery, loss of consciousness, and compression of a body part due to stroke/intoxication $[2,4,5]$. However, such cases have been sparsely reported in the literature. In this study, we present one such case of acute kidney injury (AKI) secondary to rhabdomyolysis in a patient who sustained a minor slip and fall athome.

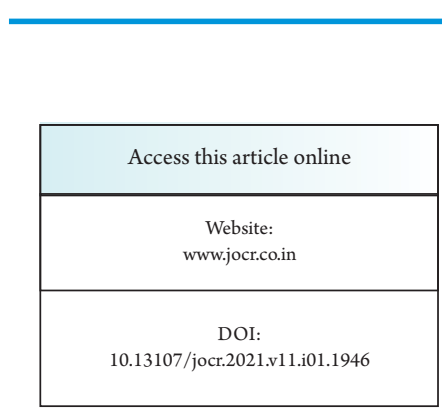

Author's Photo Gallery

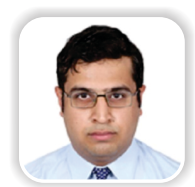

Dr. Akshat Gupta

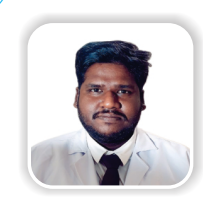

Dr. Jeshwanth N
${ }^{1}$ Department of Orthopaedic Surgery, All India Institute of Medical Sciences, Jodhpur, Rajasthan, India.

Address of Correspondence:

Dr. Akshat Gupta,

Department of Orthopaedic Surgery, All India Institute of Medical Sciences, Jodhpur, Rajasthan. India.

E-mail: mirage1.akshat@gmail.com

Journal of Orthopaedic Case Reports | pISSN 2250-0685 | eISSN 2321-3817 | Available on www.jocr.co.in | doi:10.13107/jocr.2021.v11.i01.1946 This is an Open Access article distributed under the terms of the Creative Commons Attribution Non-Commercial License (http://creativecommons.org/licenses/by-nc/3.0) which permits unrestricted non-commercial use, distribution, and reproduction in any medium, provided the original work is properly cited. 


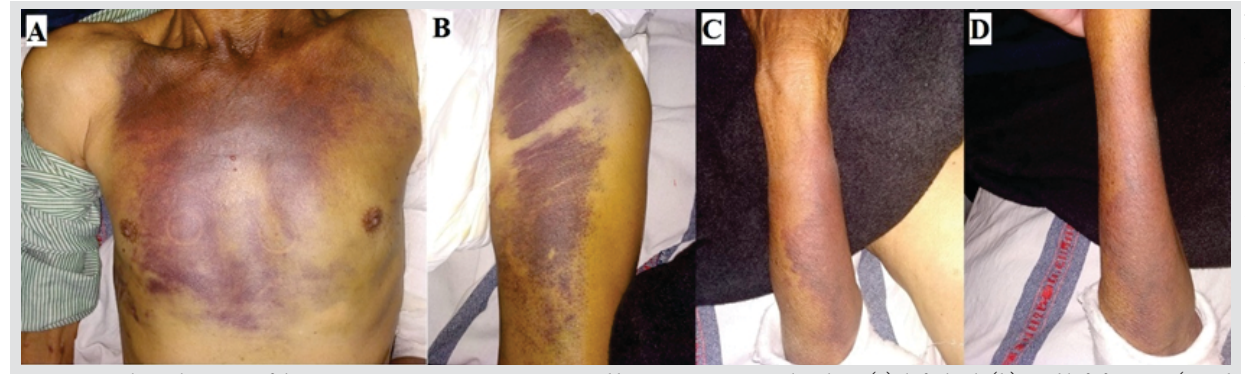

Figure 1: Clinical images of the patient: Extensive contusions and bruising seen over the chest (a), left thigh (b), and left forearm (c and d).

\section{Case Description}

The patient was a 77-year-old male who presented to the emergency with the chief complaints of sudden onset pain in his left hip and shoulder following an episode of slip and fall at home 2 days ago. He was a known case of hypertension, for which he had been taking treatment for the past 15 years. Clinical examination revealed extensive bruising over the chest, left arm, forearm, as well as the medial aspect of the entire left thigh (Fig. 1). Movements of involved hip and shoulder joints were extremely painful and restricted. There was no distal neurovascular deficit in any of the involved limbs.

Laboratory investigations revealed anemia $(\mathrm{Hb} 8.5 \mathrm{~g} / \mathrm{dl}$ ), deranged renal parameters (blood urea was $266 \mathrm{mg} / \mathrm{dl}$ and serum creatinine $3.46 \mathrm{mg} / \mathrm{dl}$ ), elevated serum potassium ( 5.73 $\mathrm{mmol} / \mathrm{L})$, and uric acid $(10.4 \mathrm{mg} / \mathrm{dl})$. Coagulation profile was within normal limits. This was initially attributed to the patient's long-standing hypertension, and hence, adequate fluid resuscitation was undertaken with a strict input-output monitoring. Serial blood gas analysis was also done. Thereafter, the patient was sent for radiological evaluation. The latter revealed fracture of the left inter-trochanteric femur with associated fracture of the left proximal humerus (Fig. 2). Contrary to the extent of contusions, X-rays did not reveal any bony injury to the chest/thigh and forearm.

The patient was closely monitored for any signs of deteriorating renal function. However, due to prompt and adequate administration of intravenous fluids (normal saline), his renal profile showed significant improvement (blood urea came down to $79 \mathrm{mg} / \mathrm{dl}$ and serum creatinine to $0.68 \mathrm{mg} / \mathrm{dl}$ ). This

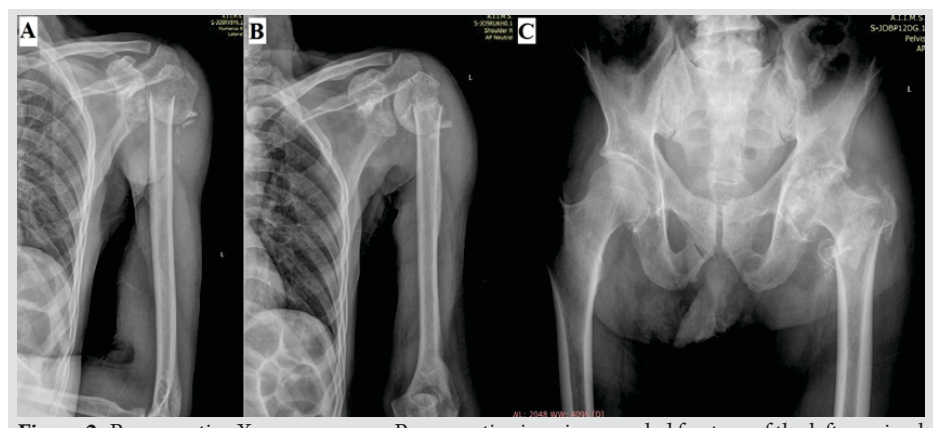

Figure 2: Pre-operative X-ray sequences: Pre-operative imaging revealed fracture of the left proximal humerus ( $a$ and $b$ ) as well as left intertrochanteric femur (c) the diagnosis.

The patient underwent closed reduction and internal fixation with the proximal femoral nail for the inter-trochanteric femur fracture (Fig. 3). However, he refused to give consent for a second surgery, and hence, proximal humerus fracture was managed non-operatively with sling immobilization, limb elevation, and analgesics. Post-operative period was uneventful and the patient was subsequently discharged after 7 days of hospitalization. At 3 months follow-up, he was able to walk with the help of crutches. There was still residual pain and stiffness in his left shoulder, for which he was on regular physiotherapy and medications.

\section{Discussion}

Crush syndrome was first described in the British Medical Journal in 1941 by Eric Bywaters and is therefore also known as Bywaters syndrome $[1,3,5,7]$. Crush injuries - war injuries, earthquakes, tsunamis, landslides, mining accidents, etc., have one thing in common - they usually result from high or extremely high-energy trauma.

Rarely, features of crush syndrome may be seen in patients sustaining low-energy traumatic injuries. Devitt et al. [8] and Daher et al. [9]. have both reported crush syndrome occurring in patients following a severe bout of alcohol consumption. In the first case, the patient was intoxicated as a result of which he passed out with his right arm hanging across a suitcase. When he subsequently presented to the emergency, he had severe pain associated with paralysis of his right upper limb. In the case reported by Daher et al., [9] the patient had consumed a large

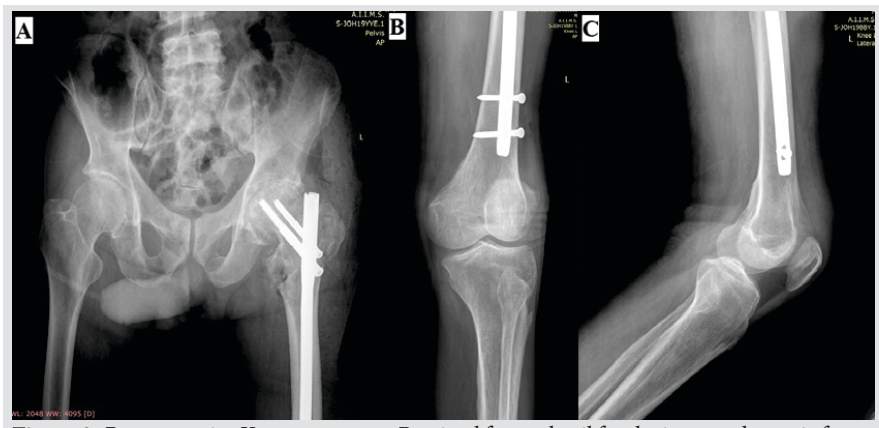

Figure 3: Post-operative $\mathrm{X}$-ray sequences: Proximal femoral nail for the intertrochanteric femu fracture $(\mathrm{a}-\mathrm{c})$. 
quantity of alcoholic beverage following a strenuous exercise. He presented to the emergency with features of compartment syndrome, oliguria, and brownish colored urine. In both the cases, urine dipstick (presence of red blood cells) and blood investigations (grossly elevated CPK) were suggestive of rhabdomyolysis. Genthon et al. [2] and Dickmann et al. [10] have each reported a case of acute kidney injury secondary to crush syndrome in patients of substance abuse. In both instances, patients were suffering from a severe psychiatric illness, for which they were on antipsychotic medications. Another unusual case was described by Tsuji et al. [11], where the patient developed features of rhabdomyolysis by sitting in the kneeling seiza position (a type of sitting posture with extreme knee flexion commonly seen in Japanese culture) for a prolonged period of time. According to the authors, this position reduces blood flow in the lower extremities thereby leading to ischemic necrosis of the soleus muscle. Immobilization of patients during surgery for extended periods of time has also been postulated to result in rhabdomyolysis. Vijay et al. [12] have published an article where they have documented myoglobinuric acute renal failure in four patients undergoing urogenital surgeries in the lithotomy/extended lithotomy positions. A brief summary of these studies and how they compare with ours is given in Table 1 .

The underlying pathophysiology at the cellular level remains the same for all cases. A part of the patient's body is subjected to increased mechanical pressure due to immobilization for a prolonged period of time. As a result, myocytes are stretched and the crush insult disrupts the $\mathrm{Na} / \mathrm{K}$ transporter of the sarcolemmal membrane which allows $\mathrm{Ca} 2+$ to move

\begin{tabular}{|c|c|c|c|c|}
\hline \multicolumn{5}{|c|}{$\begin{array}{l}\text { Table 1: A brief summary of the various causes of rhabdomyolysis in patients } \\
\text { sustaining low-energy trauma }\end{array}$} \\
\hline S. No. & Author/Year & Age/Sex & $\begin{array}{l}\text { No. of } \\
\text { cases }\end{array}$ & Cause of rhbdomyolysis \\
\hline 1 & $\begin{array}{l}\text { Daher et al . [9] } \\
\text { (2005) }\end{array}$ & $39 / \mathrm{M}$ & 1 & $\begin{array}{l}\text { Strenuous exercise followed } \\
\text { by a bout of excessive } \\
\text { alcohol intake. }\end{array}$ \\
\hline 2 & $\begin{array}{l}\text { Dickmann et al. } \\
\text { [10] (2010) }\end{array}$ & $44 / \mathrm{M}$ & 1 & $\begin{array}{l}\text { Antipsychotic (Quetiapine) } \\
\text { ingestion. }\end{array}$ \\
\hline \multirow[t]{4}{*}{3} & $\begin{array}{l}\text { Vijayet al. [12] } \\
\text { (2011) }\end{array}$ & $34 / \mathrm{M}$ & 4 & $\begin{array}{c}\text { Prolonged immobilization } \\
\text { during surgery either in the } \\
\text { lithotomy or the extended } \\
\text { lithotomy position. }\end{array}$ \\
\hline & & $28 / \mathrm{M}$ & & \\
\hline & & $16 / \mathrm{M}$ & & \\
\hline & & $33 / \mathrm{F}$ & & \\
\hline 4 & $\begin{array}{l}\text { Devitt et al. }[8] \\
\text { (2011) }\end{array}$ & $18 / \mathrm{M}$ & 1 & $\begin{array}{l}\text { Saturday night palsy } \\
\text { secondary to alcohol } \\
\text { intoxication. }\end{array}$ \\
\hline 5 & $\begin{array}{l}\text { Genthon et al. [2] } \\
\text { (2014) }\end{array}$ & $23 / \mathrm{M}$ & 1 & $\begin{array}{l}\text { Loss of consciousness } \\
\text { following substance abuse }\end{array}$ \\
\hline 6 & $\begin{array}{l}\text { Tsuji et al. }[11] \\
\text { (2014) }\end{array}$ & $52 / \mathrm{M}$ & 1 & Kneeling seiza position. \\
\hline 7 & $\begin{array}{c}\text { Present study } \\
\text { (2019) }\end{array}$ & $77 / \mathrm{M}$ & 1 & Slip and fall at home. \\
\hline
\end{tabular}

intracellularly and activate several protein-digesting enzymes. Eventually, the cell breaks down and intracellular contents potassium as well as urate, are released into the circulation. Reciprocally, $\mathrm{Ca} 2+$ and $\mathrm{Na}+$ rush into the cell. This leads to dyselectrolytemia characteristic of rhabdomyolysis hyperkalemia, hypocalcemia, and hyponatremia. Although cardiac arrhythmias (secondary to raised potassium levels) are the immediate concern, the effects on the kidney constitute a far more serious problem. There are several factors which contribute toward impairment of renal function. Sequestration of the circulating blood volume in the injured limb due to third spacing effect is one such factor. In addition, the heme present in myoglobin released from the skeletal muscle cells is nephrotoxic in nature. First, it scavenges nitric oxide (NO), thereby exacerbating pre-renal vasoconstriction. Second, the iron in heme acts as a catalyst and leads to the formation of several free radicals which are directly nephrotoxic in nature. Finally, the myoglobin filtered by the kidney's precipitates and forms Tamm-Horsfall proteins which lead to cast formation in the renal tubules $[4,5,7,13,14]$.

Diagnosis of rhabdomyolysis is usually made when the serum CPK levels are more than $1000 \mathrm{U} / \mathrm{L}$ or more than 5 times the baseline value. Their level rises $12-24 \mathrm{~h}$ after injury, peaks after 1-3 days, and usually returns to the baseline value after 6-10 days. While serum CPK levels have traditionally been considered as the best predictor of AKI, other tests such as urine and serum myoglobin levels have also been used to validate the diagnosis. In addition, a close monitoring is needed of various other blood parameters such as - serum potassium, blood urea/serum creatinine, coagulation profile, and hematocrit. Serial blood gas analysis is also needed $[1,4,5]$.

Management of AKI is traditionally accomplished through adequate resuscitation with intravenous fluids. The target urine output is $200-300 \mathrm{ml} / \mathrm{h}$. Although no recommendations exist with respect to the type of fluid needed to be used, Severs et al. [15], in their work on the management of crush syndrome, have recommended isotonic saline as the fluid of choice. The proposed infusion rates are $1 \mathrm{~L} / \mathrm{h}$ for the first $2 \mathrm{~h}$ followed by $500 \mathrm{ml} / \mathrm{h}$ beyond $2 \mathrm{~h}$. There is no consensus regarding mannitol use. However, some authors have suggested using it if fluid resuscitation alone does not produce a urine output $>300 \mathrm{ml} / \mathrm{h}$ $[5,15]$.

What was unique to our case was that the patient presented to us $48 \mathrm{~h}$ after injury and the trauma was induced by a minor slip. As he was a chronic hypertensive, the derangement in the patient's renal parameters was initially attributed to chronic renal insufficiency. However, significant improvement of the renal parameters with adequate fluid administration coupled with an elevated serum CPK level forced us to revise our initial diagnosis. Here, we would like to highlight the fact that the CPK 
was $<1000 \mathrm{U} / \mathrm{L}$. However, since the value was obtained on day 5 after trauma (when the CPK level begins to fall) and it was still more than 5 times the baseline $(171 \mathrm{U} / \mathrm{L})$, we considered it significant enough to represent rhabdomyolysis.

\section{Conclusion}

The deceptive nature of the disease, especially in geriatric patients who suffer from a multitude of comorbidities, requires a high index of suspicion when dealing with such cases. If not promptly diagnosed and treated, it can cause significant patient morbidity as well as mortality.

\section{References}

1. Rajagopalan S. Crush injuries and the crush syndrome. Med J Armed Forces India 2010;66:317-20.

2. Genthon A, Wilcox SR. Crush syndrome: A case report and review of the literature.J Emerg Med 2014;46:313-9.

3. Peiris D. A historical perspective on crush syndrome: The clinical application of its pathogenesis, established by the study of wartime crush injuries. J Clin Pathol 2017;70:27781.

4. Jagodzinski NA, Weerasinghe C, Porter K. Crush injuries and crush syndrome-a review. Part 1: The systemic injury. Trauma 2010;12:69-88.

5. Chavez LO, Leon M, Einav S, Varon J. Beyond muscle destruction: A systematic review of rhabdomyolysis for clinical practice. Crit Care 2016;20:135.

6. Li W, Qian J, Liu X, Zhang Q, Wang L, Chen D, et al. Management of severe crush injury in a front-line tent ICU after 2008 Wenchuan earthquake in China: An experience with 32 cases. Crit Care 2009; 13:R178.

7. Smith J, Greaves I. Crush injury and crush syndrome: A review.J Trauma 2003;54 Suppl 5:S226-30.

8. Devitt BM, Baker JF, Ahmed M, Menzies D, Synnott KA. Saturday night palsy or Sunday morning hangover? A case report of alcohol-induced crush syndrome. Arch Orthop Trauma Surg 2011;131:39-43.

Conflict of Interest: Nil

Source of Support: Nil

Consent: The authors confirm that informed consent was obtained from the patient for publication of this case report

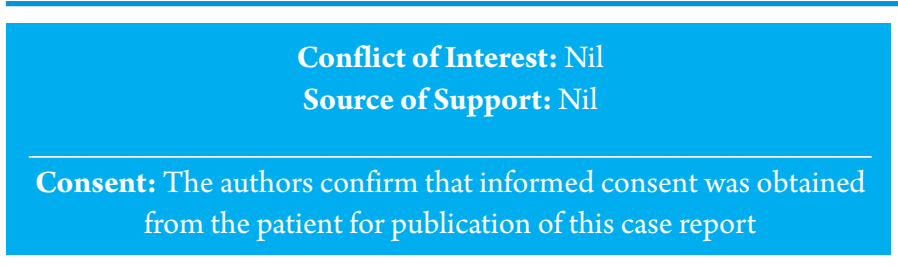

\section{Clinical Message}

Acute kidney injury secondary to rhabdomyolysis in patients sustaining low-energy trauma is a rare but life-threatening condition. It should not be confused with chronic renal insufficiency in geriatric patients many of whom are longstanding hypertensives. In such cases, a detailed history, strong clinical suspicion, and close monitoring of the patient's renal parameters are of paramount importance.

9. Daher ED, Silva GB, Brunetta DM, Pontes LB, Bezerra GP. Rhabdomyolysis and acute renal failure after strenuous exercise and alcohol abuse: Case report and literature review. Sao Paulo Med J 2005; 123:33-7.

10. Dickmann JR, Dickmann LM. An uncommonly recognized cause of rhabdomyolysis after quetiapine intoxication. Am JEmerg Med 2010;28:1060e1-2.

11. Tsuji T, Inoue S, Yamagiwa T, Morita S, Inokuchi S. A case of crush syndrome induced by the kneeling seiza position. TokaiJ Exp Clin Med 2014;39:166-8.

12. Vijay MK, Vijay P, Kundu AK. Rhabdomyolysis and myogloginuric acute renal failure in the lithotomy/exaggerated lithotomy position of urogenital surgeries. Urol Ann 2011;3:147-50.

13. Dhar D, Varghese T. Crush syndrome case report and literature review. Maced J Med Sci 2010;3:319-23.

14. Gibney RTN, Sever MS, Vanholder RC. Disaster nephrology: Crush injury and beyond. Kidney Int 2014;85:1049-57.

15. Sever MS, Vanholder RC, RDRTF of ISN Work Group on Recommendations for the Management of Crush Victims in Mass Disasters. Recommendation for the management of crush victims in mass disasters. Nephrol Dial Transplant 2012;27 Suppl 1:i1-67.

\section{How to Cite this Article}

Banerjee S, Gupta A, Jeshwanth N. Acute Kidney Injury Secondary to Rhabdomyolysis: A Rare Complication of Low-Energy Trauma. Journal of Orthopaedic Case Reports 2021 January; 11(1): 16-19. 